\title{
Open science and reproducible research
}

\author{
New reports call for scientists to share data and publishers to embrace open access
}

\author{
Trish Groves deputy editor, Fiona Godlee editor in chief
}

BMJ, London WC1H 9JR, UK

\begin{abstract}
"Scientists should communicate the data they collect and the models they create, to allow free and open access, and in ways that are intelligible, assessable and usable for other specialists ... Where data justify it, scientists should make them available in an appropriate data repository." So said the Royal Society last week, in its report Science as an Open Enterprise: Open Data for Open Science. ${ }^{1}$ The report calls for more openness among scientists and with the public and media; greater recognition of the value of data gathering, analysis, and communication; common standards for sharing information to make it widely usable; mandatory publishing of data in a reusable form to support findings; more expertise in managing and supporting the use of digital data; and new software tools to analyse data. It is time for a big shift, says the report, from the status quo where "many scientists still pursue their research through the measured and predictable steps in which they communicate their thinking within relatively closed groups of colleagues; publish their findings, usually in peer reviewed journals; file their data and then move on."
\end{abstract}

A few days earlier the UK government's working group on expanding access to published research findings, chaired by Janet Finch, recommended a "clear policy direction to support publication in open access or hybrid journals, funded by article processing charges, as the main vehicle for the publication of research, especially when it is publicly funded." ${ }^{23}$ The Finch report urges funders to establish more effective and flexible arrangements to meet the costs of publishing in open access and hybrid journals; publishers to minimise restrictions on the rights of use and reuse of text and other content, especially for non-commercial purposes; funds to be found to extend and rationalise licences and subscription arrangements for research generated in the United Kingdom and published in pay walled journals; and repositories to be developed to complement formal publishing. But the report warns that the transition to widespread open access publishing will take time and money, and meanwhile the effects of the transition on subscription based journals (which still provide the bulk of peer review and set standards for high quality publishing) must be carefully considered to minimise damage to the learned societies and publishers that run them.
As Finch explains in a podcast interview with $B M J$ editor Fiona Godlee, access to published articles and access to data are separate matters, but both can potentially benefit the public (www.bmj.com/podcast/2012/06/22/research-free-all). Indeed, major funders-including the Wellcome Trust, US National Institutes of Health, and UK Medical Research Council-have jointly stated their belief that "making research datasets available to investigators beyond the original research team in a timely and responsible manner, subject to appropriate safeguards, will generate three key benefits: faster progress in improving health, better value for money, and higher quality science." 4

These funders do not yet, however, mandate data sharing. They should. The ability of doctors to make the right decisions with patients about the benefits, harms, and costs of treatments and tests depends increasingly on high quality learning and guidance, which, in turn, depend on a robust evidence base that is as complete and as transparent as possible. We cannot rely only on results in published research articles and trial registries because they are often incompletely and selectively reported. ${ }^{5}$ Moreover, drug regulators often lack access to full data reported in confidence, let alone to publicly accessible data. ${ }^{6}$

Data sharing can greatly increase dissemination, meta-analysis, and understanding of research results; it can also aid confirmation or refutation of research through replication, ${ }^{7}$ allow better implementation of research findings, ${ }^{8}$ and increase transparency about the quality and integrity of research. It does bear some technical challenges and risks: these include potential invasion of participants' privacy and breaking of patients' confidentiality, inappropriate data manipulation, compromised academic or commercial primacy, and breach of intellectual property rights and journal copyright, but none of these should be insurmountable. ${ }^{9}$

So let's get on with it. Since 2009 the $B M J$ has asked authors to state at the end of their article whether they will allow their data to be accessed or even reanalysed by others. ${ }^{10}$ Many authors have agreed to share their anonymised data. To make it easy for authors to do this, the $B M J$ is partnering with the Dryad online repository (http://datadryad.org/), something that our sister journal BMJ Open (http://bmjopen.bmj.com/) has been doing for some time. Fifteen datasets from BMJ Open articles are already posted, as well as one from the $B M J .{ }^{11}$ 
Meanwhile, we are stepping up the BMJ's commitment to open access. After the success of last year's pilot, we have introduced article processing fees for all published research articles. Fee waivers and discounts are available for authors who are unable to pay, and editors will be unaware of whether a fee has been paid when making their decision on publication (www.bmj.com/ about-bmj/resources-authors).

With these latest high level UK reports, and the growing support of research funders around the world, ${ }^{4}$ the move towards open access has reached a tipping point. The $B M J$ was the first major general medical journal to make research articles freely available online and has maintained its commitment to open access ever since. We will continue to debate, test, implement, and promote new ways to support authors in the publication of their work, and to achieve worldwide access to research results and data (www.bmj.com/podcast/2012/06/22/research-free-all).

Competing interests: Both authors have completed the ICMJE uniform disclosure form at www.icmje.org/coi_disclosure.pdf (available on request from the corresponding author) and declare: no support from any organisation for the submitted work; both $B M J$ (where TG is deputy editor and FG is editor in chief) and BMJ Open (where TG is editor in chief) levy article processing fees to support open access to published research, and at both journals data sharing is strongly encouraged; no other relationships or activities that could appear to have influenced the submitted work.

Provenance and peer review: Commissioned; not externally peer reviewed.

1 Royal Society. Science as an open enterprise: open data for open science. 2012. http:// royalsociety.org/uploadedFiles/Royal_Society_Content/policy/projects/sape/2012-06-20SAOE.pdf.

2 Working Group on Expanding Access to Published Research Findings: the Finch group. 2012. Accessibility, sustainability, excellence: how to expand access to research publications. www.researchinfonet.org/wp-content/uploads/2012/06/Finch-Group-reportFINAL-VERSION.pdf.

3 Hawkes N. Open access to research findings will deliver huge benefits but will not be cost free, report says. BMJ 2012;344:e4248.

4 Wellcome Trust. Sharing research data to improve public health: full joint statement by funders of health research. www.wellcome.ac.uk/About-us/Policy/Spotlight-issues/Datasharing/Public-health-and-epidemiology/WTDV030690.htm.

5 Lehman R, Loder E. Missing clinical trial data. BMJ 2012;344:d8158.

6 Hart B, Lundh A, Bero L. Effect of reporting bias on meta-analyses of drug trials: reanalysis of meta-analyses. BMJ 2012;344:d7202.

7 Peng RD, Domenici F, Zeger SL. Reproducible epidemiologic research. Am J Epidemiol 2006;163:783-9.

European Medical Research Councils. Implementation of medical research in clinical practice. Forward look. 2011. www.esf.org/publications.html.

9 Groves T. BMJ Group online evidence to Royal Society call for evidence on science as an open enterprise 2011. http://royalsociety.org/policy/projects/science-public-enterprise/ call-for-evidence/.

10 Groves T. BMJ policy on data sharing. BMJ 2010;340:c564.

11 Prayle AP, Hurley MN, Smyth AR. Compliance with mandatory reporting of clinical trial results on ClinicalTrials.gov: cross sectional study. BMJ 2012;343:d7373.

Cite this as: BMJ 2012;344:e4383

๑ BMJ Publishing Group Ltd 2012 